\title{
Malaria Prevalence in Forest and Nonforest Areas of Kokrajhar District of Assam
}

\author{
Dilip C. Nath and Dimacha Dwibrang Mwchahary \\ Department of Statistics, Gauhati University, Guwahati, Gopinath Bardoloi Nagar, Jalukbri, Guwahati 14, Assam 781014, India \\ Correspondence should be addressed to Dimacha Dwibrang Mwchahary, ddmwchahary@gmail.com
}

Received 1 September 2011; Accepted 2 October 2011

Academic Editor: E. Kahan

Copyright () 2012 D. C. Nath and D. D. Mwchahary. This is an open access article distributed under the Creative Commons Attribution License, which permits unrestricted use, distribution, and reproduction in any medium, provided the original work is properly cited.

\begin{abstract}
An analysis of malaria prevalence and its trends in Kokrajhar district of Assam over the last ten years starting from 2001 to 2010 shows that the occurrence of malaria in the forest area is significantly higher than in the nonforest area $\left(\chi^{2}=7819.87, P<.0001\right)$. The transmission of malaria parasite takes place through only two Plasmodium species of $P$. falciparum (PF) and $P$. vivax (PV) in both the forest and nonforest areas of the district, and the prevalence of $P$. falciparum has been found higher. The annual blood examination rate (ABER) is relatively lower in forest area than the nonforest area while annual parasite incidence (API) of the former was much higher. Nearly one-third of the population of the district is under high risk of being affected. The malaria API and forest cover of the district during the period are negatively correlated with a coefficient of -0.57 . Special measures are necessary to contain the transmission of malaria in forest area.
\end{abstract}

\section{Introduction}

Forest malaria has been so deep rooted that it has resisted the international community's efforts for total eradication of malaria. The forests, being the reservoir of malarial disease, have been facilitating extensive malarial transmission, and the challenge is so great that even the World Health Organization had to abandon its goal of total eradication of malaria in 1969 and start the current global campaign "Rollback Malaria" [1]. Controlling malaria in forest areas has remained a challenge in many parts of Asia and South America [2]. In central Vietnam higher percentage of malarial attack takes place in forest area [3] and the same is the case in different parts of India also-higher malaria incidence in forest areas than in nonforest areas [4-6]. The northeastern part of India, to which the state of Assam belongs, is one of the regions having higher annual parasite incidence $(>5)$ [7].

The National Vector Born Disease Control Programme (NVBDCP) of the country identifies Kokrajhar as one of the eight malaria endemic districts in the state of Assam. It has contributed more than $6 \%$ of malaria cases in the last five years from 2006 to 2010 to the state malaria cases. A major part of the district is covered by forests where the inhabitants are mainly tribal people, the Bodos and the Adivasis, with some migratory population of Nepalese origin. The socioeconomic condition of villagers is poor and the people solely depend on paddy cultivation and the collection of forest products. The villages inside the forests are scattered, thinly populated, and backward in communication. These villages are difficult to approach and remain inaccessible by road during rainy season, which is pick period of malaria in the district.

The geographical area of the district is $3169 \mathrm{sq} \mathrm{km}$ and is bounded by $89^{\circ} 46^{\prime}$ to $90^{\circ} 38^{\prime}$ east longitudes and $26^{\circ} 19^{\prime}$ to $26^{\circ} 54^{\prime}$ north latitudes. The district has a contiguous forest area in its northern part while the southern part is a nonforest plain intensively cultivated with paddy. The present estimated area under reserved forests of the district is roughly $1,163 \mathrm{sq} \mathrm{km}$, which is about $37 \%$ of the total geographical area of the district. In an approximate population of 905,764 of the district, scheduled tribes constitute $33.67 \%$ of the population and $36.09 \%$ of the people are below the poverty line $[8]$. 


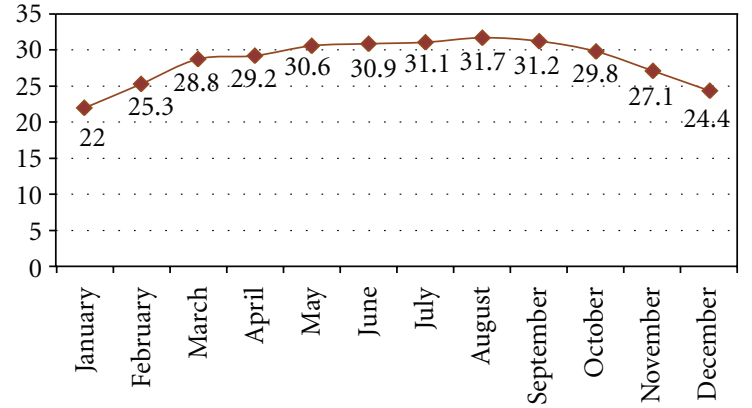

FIGURE 1: Monthly mean temperature. Source: District Agricultural Office, Kokrajhar.

Endemic diseases have been prevalent in the district for a long time [9]. Kala-azar, an endemic disease, used to sweep through the district killing thousands of people in the twenties of the 20th Century [9]. Though Kala-azar was prevalent in the past in the district, it no longer exists now and other vector-borne diseases are also very rare. But malaria remains to be endemic in the district and creates havoc among the masses.

The district has a moderate variation of temperature from $22^{\circ} \mathrm{C}$ to $32^{\circ} \mathrm{C}$, January and August being the coldest and the hottest months, respectively (Figure 1 , respective standard deviations of monthly mean temperatures are 1.0, $1.5,1.7,1.6,1.1,0.7,1.2,1.2,1.1,1.2,1.4$, and 2.1$)$. The district has got a high annual rainfall of $18626 \mathrm{~mm}$ and a high humidity of 73.5 on average [10]. These together build up a favorable condition for transmission of malaria that subsists in the district throughout the year. For this reason malaria disease occurs in the district throughout the year, the monsoon season, from May to September, being the pick period of the disease [11].

The National Rural Health Mission (NRHM), a scheme of Government of India that aims at providing valuable healthcare services to rural households all over the country, is giving special attention to the eighteen health backward states of the country, among which Assam is also one. It was launched in 2005 for a period of seven years (20052012). Effort has been made through this program to ensure effective healthcare, especially to the poor and vulnerable sections of the society. One of the key components of the National Rural Health Mission is to provide every village in the country with a trained female community health activist called an accredited social health activist (ASHA), who is selected from the village itself and given responsibility to look after the village. The Kokrajhar District National Rural Health Mission was formed in the year 2006, and it started functioning from 2007. It is trying its best to contain malaria in the district along with tackling other health issues.

\section{Objective}

The study has been taken up to analyze the malaria situation in forest area and nonforest area of the district. There is example of more prevalence of malaria in forest area than nonforest area in different parts of India [4-6, 12]. In the event that such a distinguishing situation prevails in the two areas of the district, a comparative study would be helpful in adopting effective policy and essential measures separately for forest area and nonforest area in the district for containment of malaria.

\section{Materials and Methods}

The entire district has been divided into four medical blocks: Kachugaon, Gossaigaon, Dotma, and Balajan; they are called block public health centres (BPHC). Almost the whole part of Kachugaon block primary health centre lies within forest area and parts of Dotma and Balajan Block PHCs also fall within forest area (Figure 2). In the forest area parts of Dotma and Balajan BPHCs the population is thin and there is no key health-care set-up in these parts. As such, for analysis of prevalence of malaria disease in forest area, the situation in Kachugaon BPHC may be considered to reflect the malaria situation in forest area of the district.

Henceforth, the term forest area will stand for Kachugaon $B P H C$ and nonforest area will stand for clubbed area of Gossaigaon, Dotma, and Balajan BPHCs. A figure that stands for nonforest area will represent the mean of the respective three figures of the associated three BPHCs.

For the trend analysis the secondary data on epidemiological situation reports supplied by National Vector Borne Disease Control Programme (NVBDCP), Kokrajhar district, for the period 2001-2010, has been considered and malaria indicators for different years have been calculated for all the four medical blocks. Then the mean of the indicators of the three BPHCs_-Gossaigaon, Dotma and Balajan — are found out and assigned as indicator of the nonforest area. BPHC wise population was also supplied by the same office from their annual survey. For the state figures, the epidemiological situation report of NVBDCP, Assam, has been considered.

\section{Statistical Methods and Appliances}

All data were entered in the datasheet of Microsoft Excel of 2007 version and figures have been prepared from it. Statistical tests, such as chi-square and $t$-test, have been performed with the help of VassarStats: Website for Statistical Computation: http://faculty.vassar.edu/lowry/VassarStats.html and MedCalc Statistical Software.

\section{Results}

5.1. Malaria Cases. During the epidemiological report study period 2001-2010 a total of 1,061,495 blood slides from four BPHCs (Kachugaon 197,195, others 864,300) were examined for malaria cases and out of this 66,526 slides were tested positive (Kachugaon 23,484, others 43,042). Based on the assigned definition of forest and nonforest areas, there were 23,484 cases of malaria in the forest area and 14,347 in the nonforest area out of 485,295 blood slides (forest 197,195, nonforest 288,100) examined for malaria cases, showing 


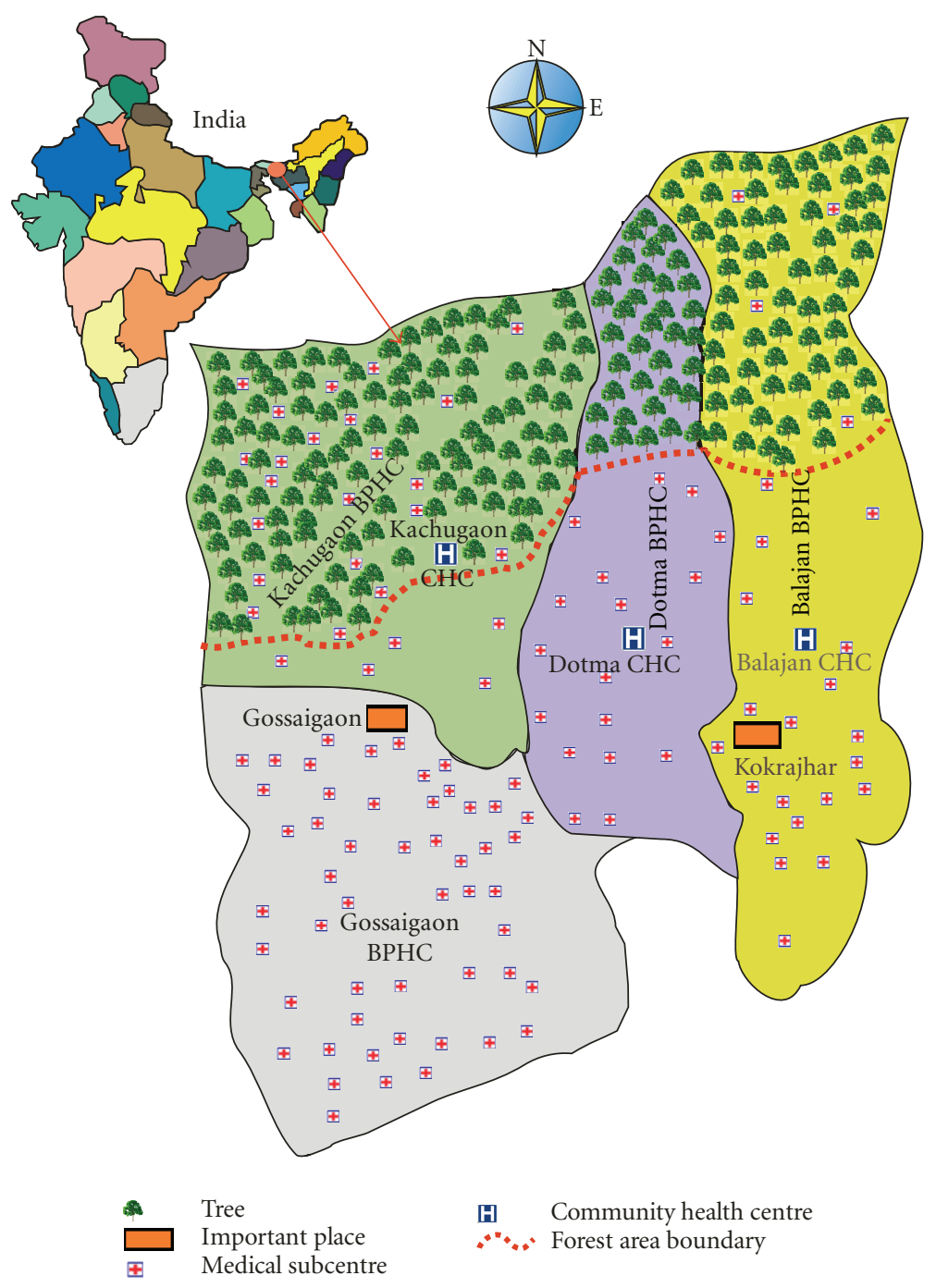

FIGURE 2: Medical blocks of Kokrajhar district.

significantly higher malaria prevalence in the forest area $\left(\chi^{2}=7819.87, P<.0001\right)$.

5.2. Annual Blood Examination Rate. During the period Kachugaon BPHC recorded much lower ABER than the other three BPHCs lying in nonforest area, the mean ABER of forest and nonforest areas being, respectively, $10 \pm 5.83$ and $11 \pm 3.85$. Up to 2007 the ABER of forest area was lower than the respective ABER of nonforest area. From 2008 onwards forest area has been provided a higher cover of ABER in comparison to nonforest area (Figure 3). Although the coverage had been up and down, ABER in both forest and nonforest areas of the district was increasing and has crossed the figure 10 (Table 1), which has been recommended by World Health Organization.

5.3. Annual Parasite Incidence. Contrary to ABER coverage situation, Kachugaon BPHC has recorded much higher API than other three BPHCs of the district since 2004 and the API of forest area had been all time higher than the API of

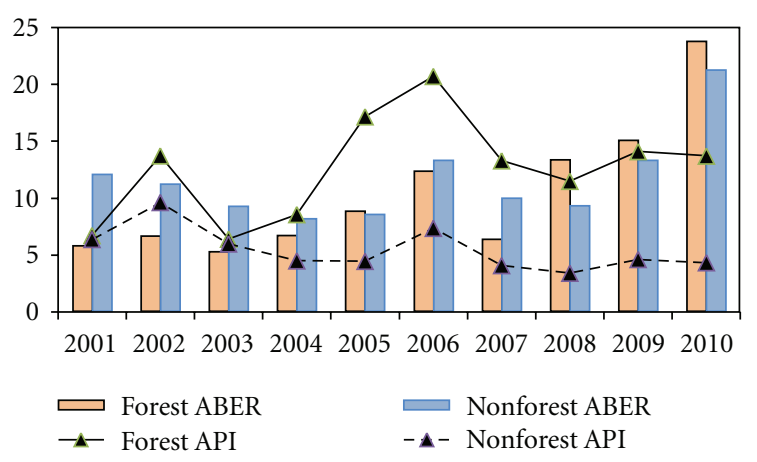

FIGURE 3: ABER and API of forest and nonforest areas.

the whole district during the whole period, suggesting that malaria parasite transmission is significantly higher in the forest area than the nonforest area $(P=.0002, t=4.61$; $d f=18$; Figure 4$)$. The API of the forest malaria varied from 6.41 (in 2003) to 20.71 (in 2006) while the range of 
TABLE 1: Block wise API and ABER.

\begin{tabular}{cccccccccccc}
\hline \multirow{2}{*}{ Year } & \multicolumn{3}{c}{ API } & \multicolumn{3}{c}{ ABER } \\
& Kachugaon & Gossaigaon & Dotma & Balajan & District & Kachugaon & Gossaigaon & Dotma & Balajan & District \\
\hline 2001 & 6.73 & 9.26 & 4.79 & 6.05 & 6.43 & 5.76 & 17.58 & 9.88 & 11.21 & 11.16 \\
2002 & 13.73 & 15.81 & 3.31 & 9.43 & 10.20 & 6.59 & 16.08 & 8.43 & 10.56 & 10.49 \\
2003 & 6.41 & 12.64 & 2.97 & 3.68 & 6.08 & 5.19 & 12.30 & 6.43 & 8.72 & 8.32 \\
2004 & 8.57 & 8.47 & 2.37 & 3.26 & 5.38 & 6.63 & 10.15 & 7.05 & 7.41 & 7.78 \\
2005 & 17.17 & 6.43 & 1.84 & 4.56 & 7.18 & 8.78 & 8.92 & 7.51 & 8.68 & 8.55 \\
2006 & 20.71 & 8.33 & 5.91 & 7.47 & 10.18 & 12.29 & 16.54 & 12.59 & 11.74 & 13.05 \\
2007 & 13.30 & 1.91 & 5.04 & 4.86 & 6.08 & 6.31 & 10.12 & 8.54 & 10.37 & 9.12 \\
2008 & 11.49 & 2.71 & 3.09 & 3.95 & 5.18 & 13.30 & 11.36 & 10.61 & 7.49 & 10.13 \\
2009 & 14.10 & 5.09 & 2.34 & 5.59 & 6.90 & 15.01 & 16.61 & 14.20 & 9.67 & 13.65 \\
2010 & 13.71 & 3.70 & 3.64 & 5.34 & 6.55 & 23.68 & 22.89 & 24.15 & 17.82 & 21.76 \\
\hline
\end{tabular}

TABLE 2: Malaria indicators of forest and nonforest areas.

\begin{tabular}{|c|c|c|c|c|c|c|c|c|c|c|c|c|}
\hline \multirow{2}{*}{ Year } & \multicolumn{6}{|c|}{ Forest area } & \multicolumn{6}{|c|}{ Nonforest area } \\
\hline & BSE & API & SPR & $\mathrm{PF}$ & SFR & PV & BSE & API & SPR & $\mathrm{PF}$ & SFR & PV \\
\hline 2001 & 9859 & 6.73 & 11.68 & 1018 & 10.33 & 134 & 43351 & 6.38 & 5.31 & 1,856 & 4.28 & 446 \\
\hline 2002 & 11885 & 13.73 & 20.85 & 1949 & 16.40 & 529 & 40782 & 9.62 & 8.65 & 2,677 & 6.56 & 851 \\
\hline 2003 & 9053 & 6.41 & 12.34 & 904 & 9.99 & 213 & 19038 & 5.99 & 6.52 & 966 & 5.08 & 275 \\
\hline 2004 & 11639 & 8.57 & 12.91 & 1370 & 11.77 & 133 & 17338 & 4.51 & 5.57 & 698 & 4.03 & 267 \\
\hline 2005 & 15600 & 17.17 & 19.54 & 2586 & 16.58 & 463 & 18480 & 4.46 & 5.26 & 770 & 4.16 & 202 \\
\hline 2006 & 22261 & 20.71 & 16.85 & 2531 & 11.37 & 1220 & 29820 & 7.36 & 5.55 & 1,343 & 4.50 & 313 \\
\hline 2007 & 11935 & 13.30 & 21.08 & 1234 & 10.34 & 1282 & 22584 & 4.09 & 4.13 & 830 & 3.68 & 104 \\
\hline 2008 & 25708 & 11.49 & 8.64 & 1298 & 5.05 & 922 & 21316 & 3.42 & 3.70 & 696 & 3.27 & 93 \\
\hline 2009 & 30750 & 14.10 & 9.40 & 1923 & 6.25 & 966 & 28540 & 4.62 & 3.50 & 883 & 3.10 & 115 \\
\hline 2010 & 48505 & 13.71 & 5.79 & 2079 & 4.29 & 730 & 46850 & 4.34 & 2.05 & 774 & 1.65 & 188 \\
\hline
\end{tabular}

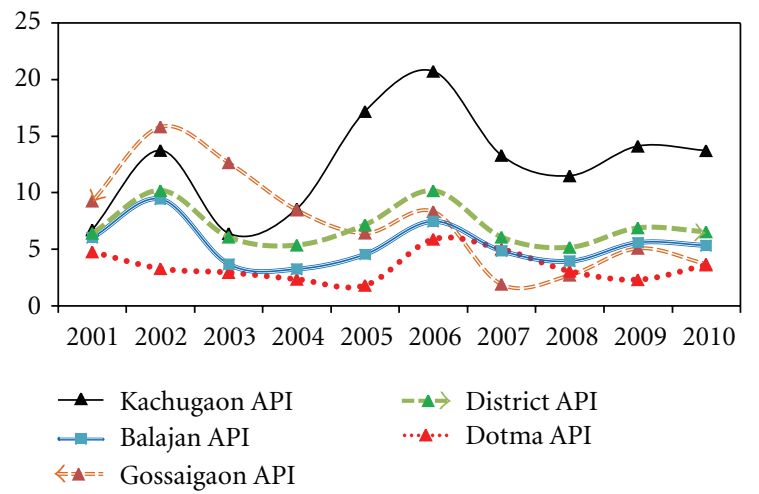

Figure 4: BPHC wise API.

nonforest malaria API was 3.42-9.62. The API of nonforest was highest during 2002 while it was lowest during 2008. There is a low-significant decreasing trend of API in both the areas $\left(\chi^{2}=2.746, d f=1, P=.0975\right.$ for forest and $\chi^{2}=3.019, d f=1, P=.0823$ for nonforest).

It is noteworthy that during the period the API of the whole district had been varying in the form of a harmonic motion with varying amplitudes. It used to increase for some years and then took to decrease for some years, repeating the same process. During 2001-2006 the amplitude of the harmonic motion was approximately 2.51 , while in the later part the amplitude has been decreasing and thus the path of API was transformed into a damped harmonic motion (Figure 5). Of course, the API of forest malaria was more fluctuating than that of nonforest area and had set a new trend line after 2006, which lies below the earlier trend line for the period 2001-2006. The API of forest area had remained always much above the API of nonforest area during the period and the malaria scenario in the district is being characterized by the malaria scenario of the forest area (Table 2).

5.4. Prevalence of Disease. There was higher prevalence of malaria disease in the forest area than nonforest area during the period $(P<.0001, t=4.93 ; d f=18)$. The mean SPR of forest area was $14 \pm 5.4$ during the period, the highest and lowest rates being in the years 2007 and 2010, while the mean SPR of nonforest area stood as $5 \pm 1.82$, the years of highest and lowest rates being 2002 and 2010. The SPR of forest area kept on fluctuating in between the range of 11.68-21.08 during 2001-2007, the mean prevalence during the period being $16 \pm 4$.14. But since 2008 the forest SPR had acquired a fast declining trend and the mean prevalence in the last three 


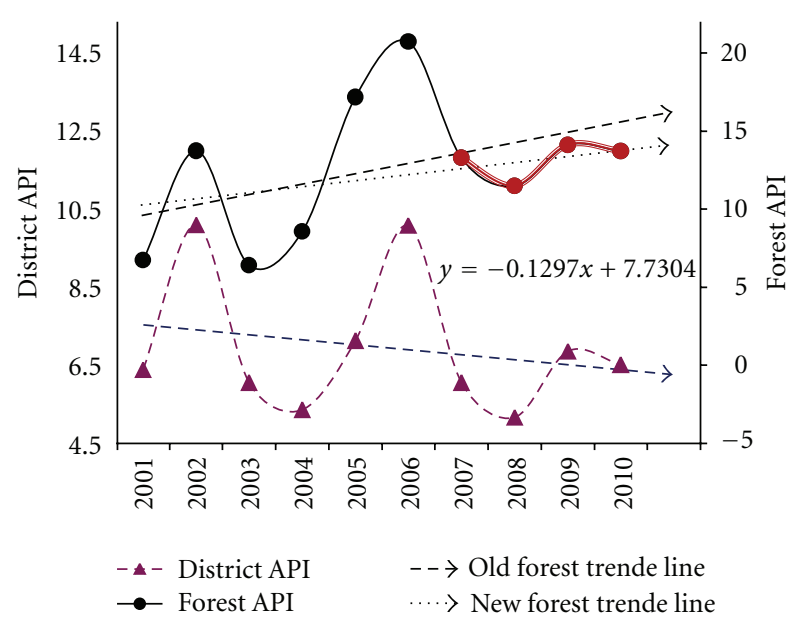

FIgURE 5: Trends of district and forest API.

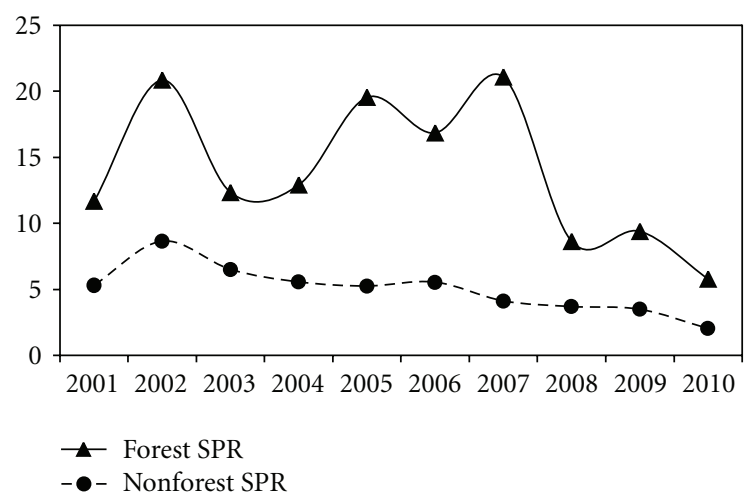

FIGURE 6: SPR of forest and nonforest areas.

years from 2008 to 2010 stood at $8 \pm 1.9$. On the other hand, the SPR of nonforest area attained its maximum during the year 2002 and after that it took to decline almost steadily and during the last three years of the period the mean prevalence was $3 \pm 0.9$ (Figure 6). There is a notable declining trend in the SPR of both the areas $\left(\chi^{2}=7.891, d f=1, P=.005\right.$ for forest and $\chi^{2}=6.959, d f=1, P=.008$ for nonforest).

5.5. Malaria High-Risk Area. The average SPR of forest area for the last three consecutive years 2008, 2009, and 2010 is $7.9 \%$, which is greater than $5 \%$. So based on the criteria of Malaria Action Programme of the country [13, 14], the entire forest area may be placed under high-risk-area category. Contrary to this, the nonforest area may be considered outside high-risk area as the SPR of the last three consecutive years is less than $5 \%$.

5.6. Dominant Malaria Species. PF species had dominated the PV species in both forest and nonforest areas $(P=.0002$, $t=4.37 ; d f=18$ for forest and $P=.0004, t=3.98$; $d f=18$ for nonforest) of the district more or less the whole period (Figure 7). During the year 2007 only the PV cases exceeded the PF cases in the forest area, after that PV cases are declining in the area. The mean ratio of PF and PV cases

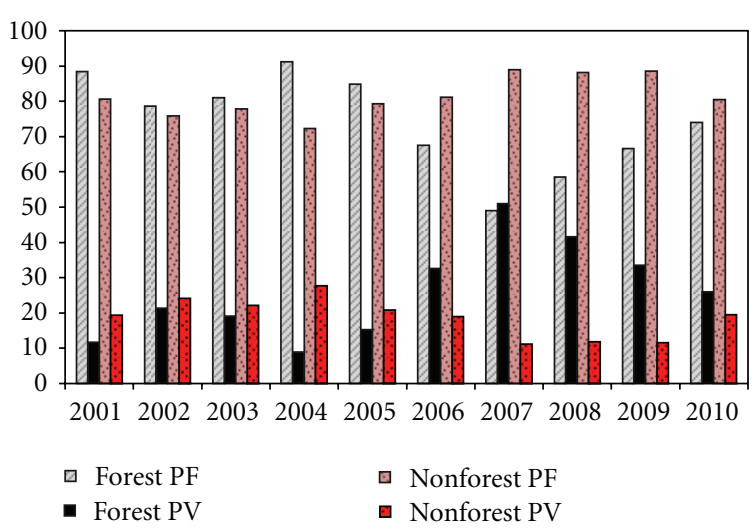

Figure 7: PF and PV of forest and nonforest areas.

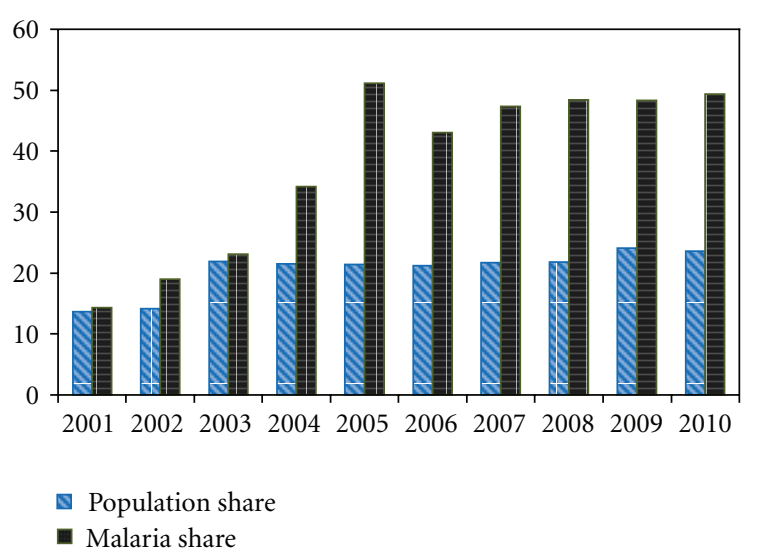

FIgURE 8: Population share versus malaria share of forest area.

in the forest area during the period was $74: 26$ while in the nonforest area it was $81: 19$, and for the whole district it was $77: 23$. The SFR of forest area kept on fluctuating from 2001 to 2005 with a mean rate of $13 \pm 3.24$, and then took to climb down gradually and in 2010 it had recorded the lowest value of 4.29. Contrary to this, the SFR of nonforest area took to decline right from 2002 almost steadily from the maximum figure 6.56 and in 2010 it recorded its lowest value of 1.65.

5.7. Population Share versus Malaria Share of Forest Area People. The forest area population has been bearing excessive share of malaria cases during the period. The malaria share of the forest area to the district is much higher than the corresponding population share. There is an increasing trend of this inconsistency of malaria and population shares. During 2001 the two shares were almost equal, but during 2010 it has risen up to greater than $2: 1$. During the whole period of study $19.88 \%$ population of the district residing in forest area were bearing $35.25 \%$ of the malaria occurred in the district (Figure 8).

5.8. District Malaria from the Perspective of State Malaria. When the malaria scenario of the district during the period 2001-2009 is compared with that of the state it is seen that 
TABLE 3: Slide collection by ASHA during 2007-2010. Source: District NRHM Office, Kokrajhar.

\begin{tabular}{lccc}
\hline Name of block PHC & No. of slides collected & No of patients treated & Percentage of positivity \\
\hline Balajan & 3967 & 3398 & 85.66 \\
Dotma & 2756 & 2264 & 82.15 \\
Kachugaon & 4678 & 4323 & 92.41 \\
Gossaigaon & 3840 & 2957 & 77.01 \\
\hline Total & 15241 & 12942 & 84.92 \\
\hline \multicolumn{4}{c}{ Monthly average slide collection: 332 nos. } \\
\hline
\end{tabular}

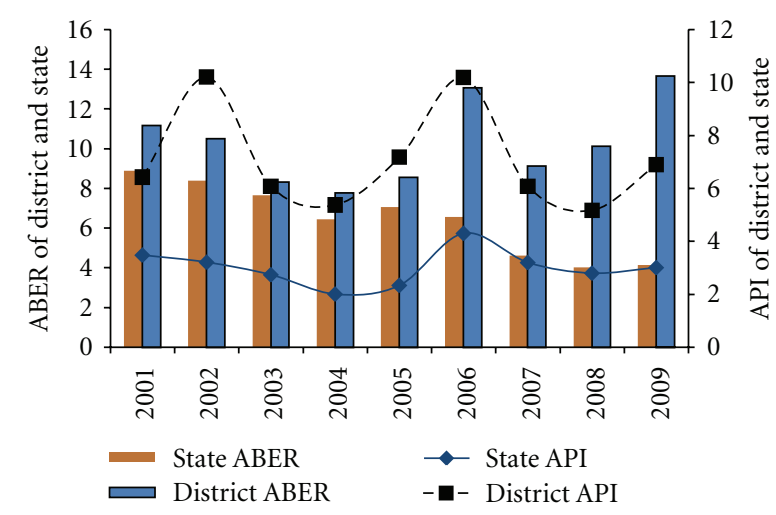

FIgURE 9: ABER and API of state and district.

for the last nine years the district has got all time higher API than the state. Every year the API of the district happens to be almost twice the API of the state. There is no trend of change of this situation. But it is encouraging that the district is maintaining all time higher ABER than the state (Figure 9).

5.9. Malaria Treatment through ASHA. ASHAs of NRHM are rendering services in the remote forest areas of the district in treating malaria. Blood slides are being collected by them from suspected patients for examination of the presence of malaria parasite, sent to clinics through multipurpose workers (MPW), and then necessary follow-up measures are taken if the slide is found positive. On average, ASHAs are collecting 332 slides per month in the district for malaria tests, of which $84.92 \%$ have been found positive (Table 3 ). Kachugaon BPHC tops the percentage of positivity with a figure of 92.41. Furthermore, NRHM has been providing malaria treatment to the people of medically backward areas of the district through mobile medical services. Annually, on average, 215 medical camps are being held in the district by Mobile Medical Unit of NRHM and on average 30,700 people are being treated annually through these camps.

\section{Discussion}

It has been observed that in the early years of the study period forest area was paid less attention in comparison to nonforest area in containing malaria, as a result of which ABER of forest area remained lower than that of nonforest area.
For an improved malaria situation a high ABER should be followed by a low API, but in the district a high ABER is being followed by a high API, indicating alarming malaria situation in the district, although there is a slightly declining trend.

Prevalence of malaria in the forest area was almost twice the prevalence in nonforest area, and sometimes even greater, every year during the period. Malaria in the forest area of the district took to decline after 2007 only while malaria in nonforest area started to decline, much earlier, after 2002. It is an encouraging indication that the SPR of both the areas remained below 10 during the last three years from 2008 to 2010, and in 2010 the SPR of both areas have attained their lowest levels.

The result of the present analysis corroborates the finding of National Institute of Malaria Research (of India) that in the forest areas inhabited by ethnic tribes, P. Falciparum proportion is 30-90\% [7]. But the outcome of this analysis is not in conformity with the findings of Singh et al. that mention PF species to be dominant in forest area of Mandla district of Madhya Pradesh in India while the nonforest area of the state was dominated by PV species [12]; rather in the case of Kokrajhar district, both the forest and nonforest areas are dominated by PF species. Singh et al. observed replacement of dominant $\mathrm{PV}$ malaria species by $\mathrm{PF}$ in Central India [15]. In Kokrajhar district, although there is no such clear trend of shifting of situation from higher to lower prevalence of PF species in both forest and nonforest areas, there is a great tendency of replacing PF by PV in forest area. During the period 2004-2007, there was a significant decline in PF cases in forest area $\left(\chi^{2}=52.603, d f=1, P<.0001\right)$, when PV cases slightly exceeded PF cases in 2007. But after that PV cases took to decline steadily in the area again.

A convincingly strong association of malaria prevalence in the forest and nonforest areas of the district dose not exist, the correlation coefficient of the two prevalence being 0.63 . The highest prevalence in the forest area occurred in the year 2007, while the same occurred in the nonforest area in 2002.

It has been observed that the process of deforestation sometimes plays a role of adverse effect on the health status of people [16]. The survival, density, and distribution of malaria mosquitoes are dramatically influenced by small changes in environmental conditions such as temperature, humidity, and the availability of suitable breeding sites; deforestation provides these favorable changes through water logging to these mosquitoes [16]. Deforestation might have 
TABLE 4: Epidemiologic situation of malaria in four blocks of Kokrajhar district during the period 2001-2010.

\begin{tabular}{|c|c|c|c|c|c|c|c|c|c|c|}
\hline $\begin{array}{l}\text { Name of } \\
\text { BPHC }\end{array}$ & Year & Population & BSE & POS & PV & $\mathrm{PF}$ & ABER & SPR & $\mathrm{PF} \%$ & API \\
\hline \multirow{10}{*}{ Kachugaon } & 2001 & 171,278 & 9859 & 1152 & 134 & 1018 & 5.76 & 11.68 & 88.37 & 6.73 \\
\hline & 2002 & 180,471 & 11885 & 2478 & 529 & 1949 & 6.59 & 20.85 & 78.65 & 13.73 \\
\hline & 2003 & 174,276 & 9053 & 1117 & 213 & 904 & 5.19 & 12.34 & 80.93 & 6.41 \\
\hline & 2004 & 175,422 & 11639 & 1503 & 133 & 1370 & 6.63 & 12.91 & 91.15 & 8.57 \\
\hline & 2005 & 177,615 & 15600 & 3049 & 463 & 2586 & 8.78 & 19.54 & 84.81 & 17.17 \\
\hline & 2006 & 181,100 & 22261 & 3751 & 1220 & 2531 & 12.29 & 16.85 & 67.48 & 20.71 \\
\hline & 2007 & 189,218 & 11935 & 2516 & 1282 & 1234 & 6.31 & 21.08 & 49.05 & 13.30 \\
\hline & 2008 & 193,225 & 25708 & 2220 & 922 & 1298 & 13.30 & 8.64 & 58.47 & 11.49 \\
\hline & 2009 & 204,840 & 30750 & 2889 & 966 & 1923 & 15.01 & 9.40 & 66.56 & 14.10 \\
\hline & 2010 & 204850 & 48505 & 2809 & 730 & 2079 & 23.68 & 5.79 & 74.01 & 13.71 \\
\hline \multirow{10}{*}{ Gossaigaon } & 2001 & 166,274 & 29227 & 1539 & 486 & 1053 & 17.58 & 5.27 & 68.42 & 9.26 \\
\hline & 2002 & 166,587 & 26786 & 2634 & 870 & 1764 & 16.08 & 9.83 & 66.97 & 15.81 \\
\hline & 2003 & 171,543 & 21099 & 2169 & 522 & 1647 & 12.30 & 10.28 & 75.93 & 12.64 \\
\hline & 2004 & 178,234 & 18085 & 1509 & 490 & 1019 & 10.15 & 8.34 & 67.53 & 8.47 \\
\hline & 2005 & 175,400 & 15650 & 1127 & 323 & 804 & 8.92 & 7.20 & 71.34 & 6.43 \\
\hline & 2006 & 185,674 & 30706 & 1547 & 348 & 1199 & 16.54 & 5.04 & 77.50 & 8.33 \\
\hline & 2007 & 187,507 & 18983 & 358 & 39 & 319 & 10.12 & 1.89 & 89.11 & 1.91 \\
\hline & 2008 & 189,554 & 21528 & 514 & 70 & 444 & 11.36 & 2.39 & 86.38 & 2.71 \\
\hline & 2009 & 228,674 & 37990 & 1163 & 159 & 1004 & 16.61 & 3.06 & 86.33 & 5.09 \\
\hline & 2010 & 241689 & 55320 & 895 & 216 & 679 & 22.89 & 1.62 & 75.87 & 3.70 \\
\hline \multirow{10}{*}{ Dotma } & 2001 & 138,155 & 13650 & 662 & 56 & 606 & 9.88 & 4.85 & 91.54 & 4.79 \\
\hline & 2002 & 139,393 & 11757 & 462 & 41 & 421 & 8.43 & 3.93 & 91.13 & 3.31 \\
\hline & 2003 & 140,516 & 9042 & 417 & 83 & 334 & 6.43 & 4.61 & 80.10 & 2.97 \\
\hline & 2004 & 141,680 & 9989 & 336 & 72 & 264 & 7.05 & 3.36 & 78.57 & 2.37 \\
\hline & 2005 & 143,088 & 10745 & 263 & 47 & 216 & 7.51 & 2.45 & 82.13 & 1.84 \\
\hline & 2006 & 150,528 & 18955 & 890 & 168 & 722 & 12.59 & 4.70 & 81.12 & 5.91 \\
\hline & 2007 & 152,720 & 13046 & 769 & 65 & 704 & 8.54 & 5.89 & 91.55 & 5.04 \\
\hline & 2008 & 153,478 & 16280 & 474 & 76 & 398 & 10.61 & 2.91 & 83.97 & 3.09 \\
\hline & 2009 & 157,143 & 22314 & 367 & 66 & 301 & 14.20 & 1.64 & 82.02 & 2.34 \\
\hline & 2010 & 157286 & 37987 & 572 & 123 & 449 & 24.15 & 1.51 & 78.50 & 3.64 \\
\hline \multirow{10}{*}{ Balajan } & 2001 & 777,869 & 87176 & 4706 & 796 & 3910 & 11.21 & 5.40 & 83.09 & 6.05 \\
\hline & 2002 & 793,757 & 83803 & 7488 & 1643 & 5845 & 10.56 & 8.94 & 78.06 & 9.43 \\
\hline & 2003 & 309,380 & 26974 & 1138 & 220 & 918 & 8.72 & 4.22 & 80.67 & 3.68 \\
\hline & 2004 & 322,943 & 23941 & 1052 & 240 & 812 & 7.41 & 4.39 & 77.19 & 3.26 \\
\hline & 2005 & 334,682 & 29045 & 1525 & 236 & 1289 & 8.68 & 5.25 & 84.52 & 4.56 \\
\hline & 2006 & 338,873 & 39798 & 2531 & 424 & 2107 & 11.74 & 6.36 & 83.25 & 7.47 \\
\hline & 2007 & 344,618 & 35724 & 1674 & 207 & 1467 & 10.37 & 4.69 & 87.63 & 4.86 \\
\hline & 2008 & 349,159 & 26140 & 1380 & 134 & 1246 & 7.49 & 5.28 & 90.29 & 3.95 \\
\hline & 2009 & 261,752 & 25316 & 1464 & 119 & 1345 & 9.67 & 5.78 & 91.87 & 5.59 \\
\hline & 2010 & 265148 & 47244 & 1417 & 224 & 1193 & 17.82 & 3.00 & 84.19 & 5.34 \\
\hline
\end{tabular}

been a reason behind changes in malaria transmission in the highlands of Kenya [17]. In present days Kokrajhar district is facing a massive deforestation. During the last eight years, from 1999 to 2007, there has been a deforestation of an area of $467 \mathrm{sq} \mathrm{km}$ [18]. This may have played a role in accelerating malaria prevalence in the district. Furthermore, poor socioeconomic condition of the people is a determinant of malaria prevalence [17]. Majority of the people residing in the forest area are living below the poverty line and they are educationally backward. This condition is facilitating higher malaria in the forest area.

The policy for controlling malaria in the country undertaken by National Vector Borne Disease Control Program is homogeneous for all people and areas. So it implies that the 
TABLE 5: Epidemiologic situation of malaria in forest area, nonforest area and whole district during the period 2001-2010.

\begin{tabular}{|c|c|c|c|c|c|c|c|c|c|c|}
\hline Name of Area & Year & Population & BSE & POS & PV & $\mathrm{PF}$ & ABER & SPR & $\mathrm{PF} \%$ & API \\
\hline \multirow{10}{*}{$\begin{array}{l}\text { Forest area } \\
\text { (Kachugaon } \\
\text { BPHC) }\end{array}$} & 2001 & 171,278 & 9859 & 1152 & 134 & 1018 & 5.76 & 11.68 & 88.37 & 6.73 \\
\hline & 2002 & 180,471 & 11885 & 2478 & 529 & 1949 & 6.59 & 20.85 & 78.65 & 13.73 \\
\hline & 2003 & 174,276 & 9053 & 1117 & 213 & 904 & 5.19 & 12.34 & 80.93 & 6.41 \\
\hline & 2004 & 175,422 & 11639 & 1503 & 133 & 1370 & 6.63 & 12.91 & 91.15 & 8.57 \\
\hline & 2005 & 177,615 & 15600 & 3049 & 463 & 2586 & 8.78 & 19.54 & 84.81 & 17.17 \\
\hline & 2006 & 181,100 & 22261 & 3751 & 1220 & 2531 & 12.29 & 16.85 & 67.48 & 20.71 \\
\hline & 2007 & 189,218 & 11935 & 2516 & 1282 & 1234 & 6.31 & 21.08 & 49.05 & 13.30 \\
\hline & 2008 & 193,225 & 25708 & 2220 & 922 & 1298 & 13.30 & 8.64 & 58.47 & 11.49 \\
\hline & 2009 & 204,840 & 30750 & 2889 & 966 & 1923 & 15.01 & 9.40 & 66.56 & 14.10 \\
\hline & 2010 & 204850 & 48505 & 2809 & 730 & 2079 & 23.68 & 5.79 & 74.01 & 13.71 \\
\hline \multirow{10}{*}{$\begin{array}{l}\text { Nonforest area } \\
\text { (mean of } \\
\text { Gossaigaon, } \\
\text { Dotma, and } \\
\text { Balajan BPHCs) }\end{array}$} & 2001 & 360,766 & 43,351 & 2,302 & 446 & 1,856 & 12.02 & 5.31 & 80.63 & 6.38 \\
\hline & 2002 & 366,579 & 40,782 & 3,528 & 851 & 2,677 & 11.13 & 8.65 & 75.87 & 9.62 \\
\hline & 2003 & 207,146 & 19,038 & 1,241 & 275 & 966 & 9.19 & 6.52 & 77.85 & 5.99 \\
\hline & 2004 & 214,286 & 17,338 & 966 & 267 & 698 & 8.09 & 5.57 & 72.32 & 4.51 \\
\hline & 2005 & 217,723 & 18,480 & 972 & 202 & 770 & 8.49 & 5.26 & 79.21 & 4.46 \\
\hline & 2006 & 225,025 & 29,820 & 1,656 & 313 & 1,343 & 13.25 & 5.55 & 81.08 & 7.36 \\
\hline & 2007 & 228,282 & 22,584 & 934 & 104 & 830 & 9.89 & 4.13 & 88.90 & 4.09 \\
\hline & 2008 & 230,730 & 21,316 & 789 & 93 & 696 & 9.24 & 3.70 & 88.18 & 3.42 \\
\hline & 2009 & 215,856 & 28,540 & 998 & 115 & 883 & 13.22 & 3.50 & 88.51 & 4.62 \\
\hline & 2010 & 221,374 & 46,850 & 961 & 188 & 774 & 21.16 & 2.05 & 80.48 & 4.34 \\
\hline \multirow{10}{*}{ Whole district } & 2001 & $1,253,576$ & 139912 & 8059 & 1472 & 6587 & 11.16 & 5.76 & 81.73 & 6.43 \\
\hline & 2002 & $1,280,208$ & 134231 & 13062 & 3083 & 9979 & 10.49 & 9.73 & 76.40 & 10.20 \\
\hline & 2003 & 795,715 & 66168 & 4841 & 1038 & 3803 & 8.32 & 7.32 & 78.56 & 6.08 \\
\hline & 2004 & 818,279 & 63654 & 4400 & 935 & 3465 & 7.78 & 6.91 & 78.75 & 5.38 \\
\hline & 2005 & 830,785 & 71040 & 5964 & 1069 & 4895 & 8.55 & 8.40 & 82.08 & 7.18 \\
\hline & 2006 & 856,175 & 111720 & 8719 & 2160 & 6559 & 13.05 & 7.80 & 75.23 & 10.18 \\
\hline & 2007 & 874,063 & 79688 & 5317 & 1593 & 3724 & 9.12 & 6.67 & 70.04 & 6.08 \\
\hline & 2008 & 885,416 & 89656 & 4588 & 1202 & 3386 & 10.13 & 5.12 & 73.80 & 5.18 \\
\hline & 2009 & 852,409 & 116370 & 5883 & 1310 & 4573 & 13.65 & 5.06 & 77.73 & 6.90 \\
\hline & 2010 & 868,973 & 189,056 & 5,693 & 1293 & 4,400 & 21.76 & 3.01 & 77.29 & 6.55 \\
\hline
\end{tabular}

different malaria situation in the forest and nonforest areas of the district is not due to policy, but rather it is due to the forest condition. The practical malaria situation prevailing in forest and nonforest areas of the district suggests that there is a necessity of separate policies for these two areas in regard to containment of malaria.

There has been a notable improvement in controlling malaria after NRHM became fully functional in the district from 2007. It made efforts to contain malaria in the forest area and accordingly from 2008 the ABER of forest area rose above that of nonforest area. Distribution of insecticide treated bed nets in the malaria-prone areas of the district started in the later part of 2007 and following this a sudden decline in malaria prevalence from 21.08 in 2007 to 8.64 in 2008 was observed in the forest area.

Accredited Social Health Activist of NRHM has been able to bridge the gap between common people and health facilities available to them. Through ASHA health department can now explain the health situation to the villagers in their own language and persuade them to avail of the health facilities available to them. The ASHA Kit has been able to change the attitude of the people who are socially, demographically, and educationally backward that prevent them from seeking modern medicine to alleviate their plight. Earlier, tribal people used to approach their traditional Oja (medicine man) or Gonok (event teller) for their treatment as they were the only accessible and approachable healers for them. For treating malaria the local communities of the district used some medicinal plants available in the forests in their vicinity as other local communities of Assam used to do [19]. But now ASHA is more easily approachable to them for their health issues and since medicines for preliminary treatment of different diseases are available to them through ASHA, the tribal villagers have started to choose modern medicines as a reliable option for their treatment. Thus the ASHA kit has been able to change even their health-seeking behavior, making them more dependent on modern medicine rather than on superstitions and traditional treatments. 


\section{Conclusion}

The analysis of malaria data of ten years in Kokrajhar district for observing trends reveals that malaria situation in the district still persists casting a gloomy picture in the district in general and the forest area in particular. Despite the malaria department's improved control measures such as comprehensive programs of vector control, surveillance and treatment and services of NRHM, there is still a preponderance of the disease in the district and the situation is under par when compared to the state situation. As forest area is the main donor to district malaria, a more rigorous measure is needed to combat malaria in the forest area. Since it is the pattern of the disease to decline for some years and then rise up again, there should be enough preparation during remission period so that the health departments can combat the disease when it takes to rise again in the following years.

\section{Appendix}

For more details see Tables 4 and 5 .

\section{Abbreviations, Acronyms and Definitions}

\author{
PV: $\quad$ Plasmodium vivax \\ PF: Plasmodium falciparum \\ BSE: Blood slides examined (number of blood \\ slides examined tested for presence of \\ malaria parasite) \\ POS: Positive (number of confirmed malaria \\ positive cases) \\ SFR: $\quad$ Slide falciparum rate $=(\mathrm{PF} / \mathrm{BSE}) \times 100$ \\ SPR: Slide positivity rate $=(\mathrm{POS} / \mathrm{BSE}) \times 100$ \\ ABER: Annual blood examination rate $=$ \\ (BSE/Population) $\times 100$ \\ API: Annual parasite incidence $=$ \\ (POS/Population) $\times 1000$.
}

\section{Acknowledgments}

The authors are thankful to the authorities of the National Vector Borne Disease Control Programme and National Rural Health Mission of Kokrajhar District for providing the epidemiology situation report on malaria and related information.

\section{References}

[1] A. K. C. Hanibelsz, Forest malaria and poverty, Minor thesis, RMIT University School of Social Science, Melbourne, Australia, 2004.

[2] "Forest malaria in Southeast Asia," in Proceedings of an informal Consultative Meeting WHO/MRC, V. P. Sharma and A. V. Kondrashin, Eds., New Delhi, India, February, 1991.

[3] A. Erhart, N. D. Thang, P. Van Ky et al., "Epidemiology of forest malaria in central Vietnam: a large scale cross-sectional survey," Malaria Journal, vol. 4, article 58, 2005.

[4] Malaria Situation in India, 2009 : At a Glance, Regional Office for South-East Asia, World Health Organization, 2009.
[5] K. S. Sharma, P. K. Tyagi, K. Padhan et al., "Epidemiology of malaria transmission in forest and plain ecotype villages in Sundargarh District, Orissa, India," Royal Society of Tropical Medicine and Hygiene, vol. 100, no. 10, pp. 917-925, 2006.

[6] R. P. Shukla, S. N. Sharma, V. K. Kohli, N. Nanda, V. P. Sharma, and S. K. Subbarao, "Dynamics of malaria transmission under changing ecological scenario in and around Nanak Matta Dam, Uttaranchal, India," The Indian Journal of Malariology, vol. 38, no. 3-4, pp. 91-98, 2001.

[7] Estimation of True Malaria Burden in India, A Profile of National Institute of Malaria Research, Indian Council of Medical Research, New Delhi, India.

[8] Population Census of India, 2001 and District Rural Development Agency Report, Kokrajhar District, 2010.

[9] M. C. Jacob, Working Plan for Kachugaon Forest Division from 1939 to1948, Shillong, India, 1939.

[10] Daily rainfall and temperature records, District Agricultural Office, Kokrajhar.

[11] Monthly records, Kokrajhar district National Vector Borne Disease Control Programme.

[12] N. Singh, O. P. Singh, and V. P. Sharma, "Dynamics of malaria transmission in forested and deforested regions of Mandla district, central India (Madhya Pradesh)," Journal of the American Mosquito Control Association, vol. 12, no. 2, pp. 225-234, 1996.

[13] Malaria Action Plane, Government of India, 1995.

[14] V. Dev, A. P. Dash, and K. Khound, "High-risk areas of malaria and prioritizing interventions in Assam," Current Science, vol. 90, no. 1, pp. 32-36, 2006.

[15] N. Singh, A. C. Nagpal, A. Saxena, and M. P. Singh, "Changing scenario of malaria in central India, the replacement of Plasmodium vivax by Plasmodium falciparum (1986-2000)," Tropical Medicine and International Health, vol. 9, no. 3, pp. 364-371, 2004.

[16] J. Yasuoka and R. Levins, "Impact of deforestation and agricultural development on anopheline ecology and malaria epidemiology," The American Journal of Tropical Medicine and Hygiene, vol. 76, no. 3, pp. 450-460, 2007.

[17] A. Niringiye and O. G. Douglason, "Environmental and socioeconomic determinants of malaria prevalence in Uganda," Research Journal of Environmental and Earth Sciences, vol. 2, no. 4, pp. 194-198, 2010.

[18] State Forest Reports 1999, 2001, 2003, 2005, 2009, Forest Survey of India.

[19] N. Namsaa, M. Mandala, and S. Tangjang, "Anti-malarial herbal remedies of northeast India, Assam: an ethnobotanical survey," Journal of Ethnopharmacology, vol. 133, pp. 565-572, 2011. 


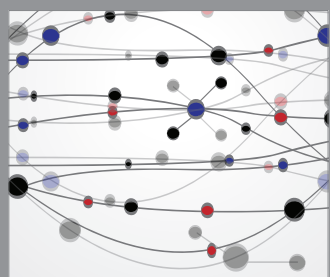

The Scientific World Journal
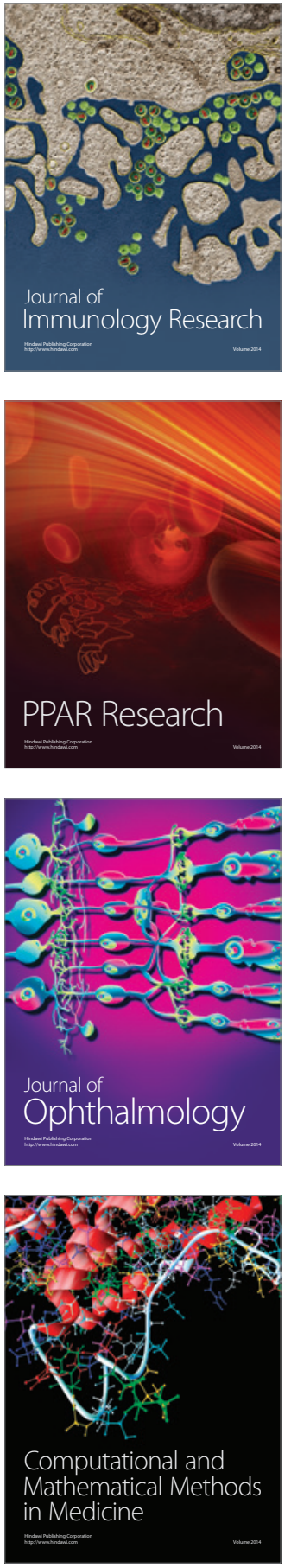

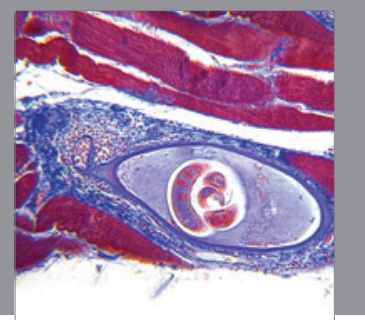

Gastroenterology

Research and Practice
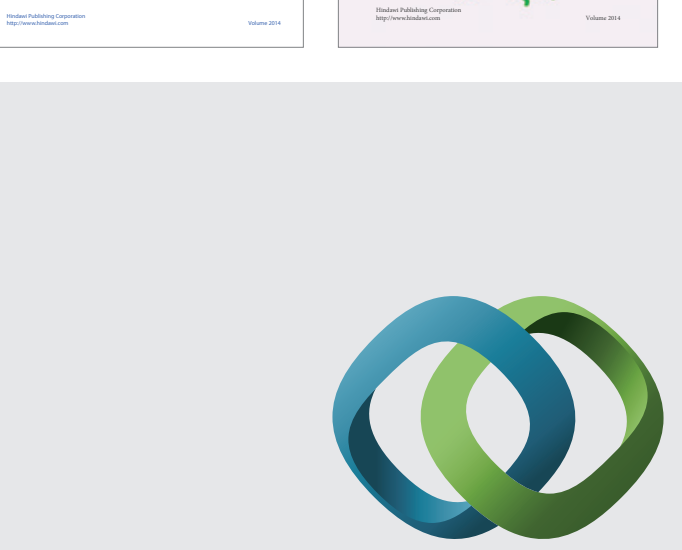

\section{Hindawi}

Submit your manuscripts at

http://www.hindawi.com
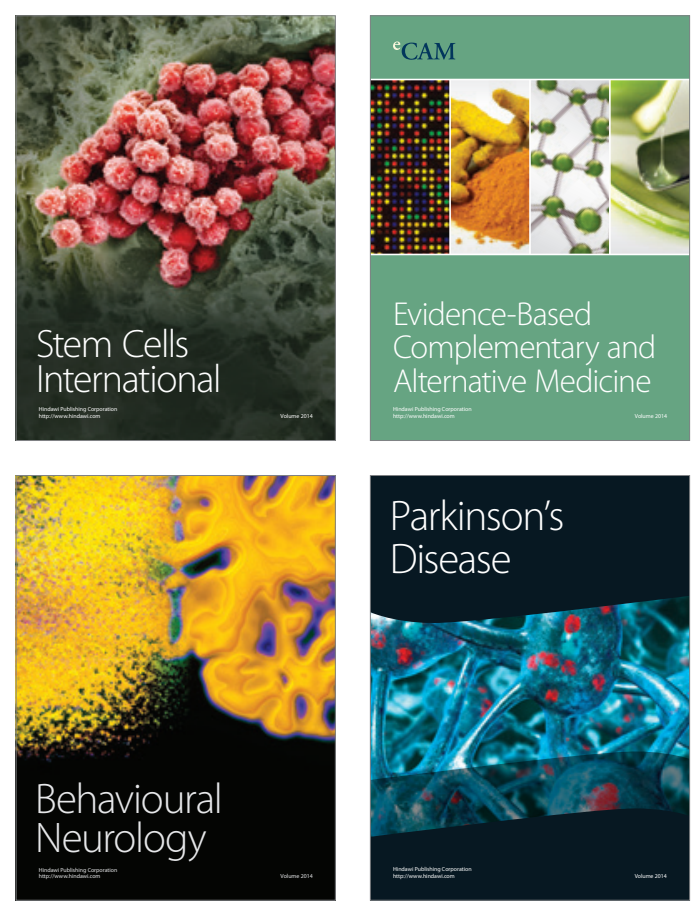

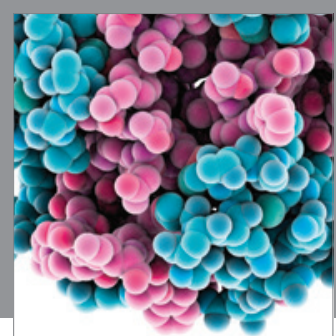

Journal of
Diabetes Research

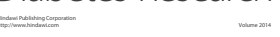

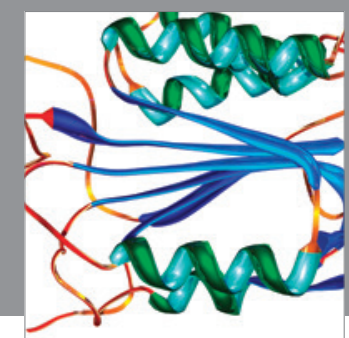

Disease Markers
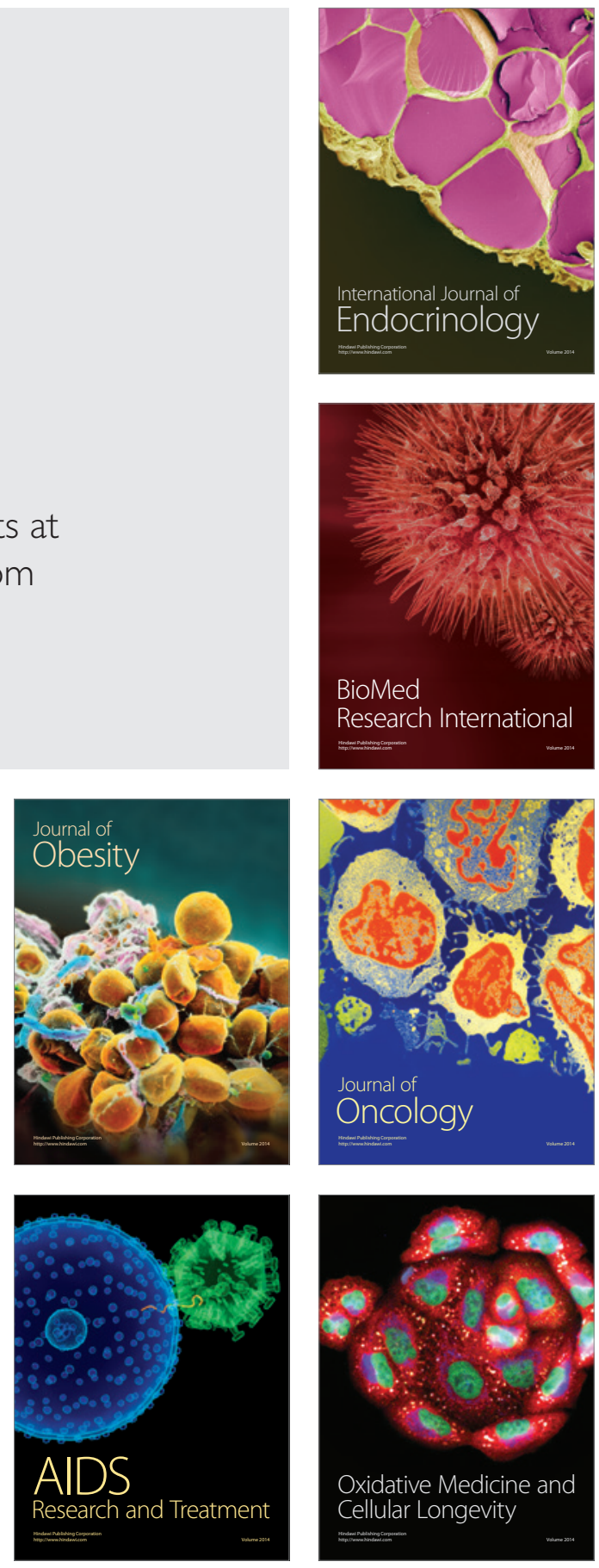